\title{
Piezoelectric Power Harvesting Process via Phase Changes of Low-Boiling-Point Medium Together with Water for Recovering Low-Temperature Heats
}

\author{
Seiichi Deguchi1 ${ }^{*}$, Akinori Miyajima', Hajime Arimura1, Haruna Banno', Noriyuki Kobayashi', \\ Norifumi Isu' ${ }^{2}$, Kentaro Takagi ${ }^{3}$, Tsuyoshi Inoue ${ }^{3}$, Takashi Nozoe ${ }^{4}$, Seigo Saito ${ }^{4}$, Takahiko Sano ${ }^{4}$ \\ ${ }^{1}$ Department of Chemical Process Engineering, Nagoya University, Nagoya, Japan \\ ${ }^{2}$ Analysis \& Assessment Center, LIXIL Corporation, Noda, Japan \\ ${ }^{3}$ Department of Mechanical Systems Engineering, Nagoya University, Nagoya, Japan \\ ${ }^{4}$ Fuji Ceramics Corporation, Fujinomiya, Japan \\ Email: *deguchi.seiichi@material.nagoya-u.ac.jp
}

How to cite this paper: Deguchi, S., Miyajima, A., Arimura, H., Banno, H., Kobayashi, N., Isu, N., Takagi, K., Inoue, T., Nozoe, T., Saito, S. and Sano, T. (2018) Piezoelectric Power Harvesting Process via Phase Changes of Low-Boiling-Point Medium Together with Water for Recovering Low-Temperature Heats. Journal of Power and Energy Engineering, 6, 65-77. https://doi.org/10.4236/jpee.2018.611006

Received: July 5, 2018

Accepted: November 24, 2018

Published: November 27, 2018

Copyright $\odot 2018$ by authors and Scientific Research Publishing Inc. This work is licensed under the Creative Commons Attribution International License (CC BY 4.0).

http://creativecommons.org/licenses/by/4.0/ (c) (i) Open Access

\begin{abstract}
Low-temperature thermal energy conversions down to exergy zero to electric power must contribute energy sustainability. That is to say, reinforcements of power harvesting technologies from extremely low temperatures less than 373 $\mathrm{K}$ might be at least one of minimum roles for the current generations. Then, piezoelectric power harvesting process for recovering low-temperature heats was invented by using a unique biphasic operating medium of an underlying water-insoluble/low-boiling-point medium (i.e. NOVEC manufactured by $3 \mathrm{M}$ Japan Ltd.) in small quantity and upper-layered water in large quantity. The higher piezoelectric power harvesting densities were naturally revealed with an increase in heating temperatures. Excessive cooling of the operating medium deteriorated the power harvesting efficiency. The denser operating medium was surpassingly helpful to the higher piezoelectric power harvesting density. Concretely, only about $5 \%$ density increase of main operating medium (i.e. water with dissolving alum at $0.10 \mathrm{~mol} / \mathrm{dm}^{3}$ ) came to the champion piezoelectric power harvesting density of $92.6 \mathrm{pW} / \mathrm{dm}^{2}$ in this study, which was about 1.4 times compared to that with the original biphasic medium of pure water together with a small quantity of NOVEC.
\end{abstract}

\section{Keywords}

Piezoelectric Power Generation, Low-Temperature Heat Recovery, Biphasic Medium, Phase Change, Multiphase Flow, Power Harvesting 


\section{Introduction}

Thermodynamic interests are to approach Carnot efficiencies in any thermal energy converting processes, thermal energy conversions down to exergy zero and practical power generators operated under extremely low temperatures, especially less than $373 \mathrm{~K}$. Therefore, we have focused on power generators based on thermoelectric, liquid turbine and piezoelectric driven by low-temperature heats below $373 \mathrm{~K}$ in the aim of contributing a great deal to energy sustainability [1] [2] [3] [4]. Among them, the piezoelectric power generation is called as "power harvesting" since most of the works have been focused on dilute renewable energies, such as vibrations and fluctuations of forces, hydraulic power, wind force and raindrop impacts as its recovering source energies [5]-[14]. There is no investigation to apply piezoelectric elements for recovering low-temperaturewaste-heats so far as the authors know.

As one of reinforcements of power harvesting technologies from lowtemperature-waste-heats, the authors invented a primal piezoelectric power generator (PEG) [4] [15] [16]. Briefly describing, the primal PEG mainly consists of two airtight vessels connected by a tube through a battery-friendly valve. One vessel is an evaporator containing a small amount of an operating medium possessing a low-boiling-point less than $373 \mathrm{~K}$, such as pentane, methanol and ethanol. Another vessel having a rectangular parallelepiped shape is a power generator, containing a massive amount of the same operating medium. Piezoelectric elements exposed to the medium are attached on four side walls of the power generator. When the valve is opened, the medium vapor with its saturated pressure is transferred from the evaporator soaked into a heating source to a dead space at a top part of the power generator at an ambient temperature, resulting to piezoelectric power generation owing to the piezoelectric elements' bending. When the valve is closed, the vapor is condensed by releasing its latent heat to the liquid medium inside the power generator, resulting to liquid pressure decrease, that is to say, piezoelectric power generation, because the elements come back to their original shapes. Infrequently, a small amount of the liquid medium is conveyed from the power generator to the evaporator by a pump needing much less power to work.

Table 1 summarizes the characteristics of the primal PEG together with further requirements and advancements.

As described both in the preceding paragraph and in Table 1, the primal PEG requires power consuming devices of the electromagnetic valve and diaphragm micro pump since it is dichotomous system composed of the evaporator and power generator where the operating medium is traversed. Furthermore, the operating medium is obliged to be conveyed through intermittent/sequential operations because of system constraints, which limit a vapor pressure impressing frequency less than $1 \mathrm{~Hz}$, resulting to inefficient performances of the piezoelectric elements attached. Consequently, further requirements and advancements listed up in Table 1 must be needed to upgrade the PEG from lowtemperature-waste-heats up to a practical stage. 
Table 1. Characteristics of primal PEG with further requirements and advancements.

\begin{tabular}{|c|c|}
\hline Characteristics of primal PEG & Further requirements and advancements \\
\hline $\begin{array}{c}\text { dichotomous system } \\
\text { (evaporator and power generator) }\end{array}$ & simplification \\
\hline $\begin{array}{l}\text { utilizations of devices consuming } \\
\text { electricity slightly (electromagnetic } \\
\text { valve and diaphragm micro pump) }\end{array}$ & no external power consuming devices \\
\hline $\begin{array}{l}\text { low vapor pressure impressing frequency } \\
(<1 \mathrm{~Hz}) \text { dominated by mass transfers }\end{array}$ & $\begin{array}{l}\text { further higher force impressing } \\
\text { frequency close to resonant } \\
\text { frequency of piezoelectric element }\end{array}$ \\
\hline intermittent/sequential operations & simultaneous operations \\
\hline
\end{tabular}

In this study, the two airtight vessels composing the primal PEG have been firstly combined for systematical simplicity and benefit of eliminating all the power consuming devices. A biphasic medium composed of an underlying water-insoluble/extremely-low-boiling-point medium (i.e. NOVEC manufactured by $3 \mathrm{M}$ Japan Ltd.) in small quantity and upper-layered water in large quantity has been applied as the operating medium [1] [2] [3]. Simultaneous repetitions of vaporization and condensation of the NOVEC inside the main medium of water have been expected to take place, promising a continuous piezoelectric power generation [17] [18]. Moreover, the force impressing frequency is certified to approach to a resonant frequency of the piezoelectric element in $\mathrm{MHz}$ order because boiling phenomena have been reported to occur in a range between $10^{2}$ and $10^{5} \mathrm{~Hz}$, resulting to high performances of a prototype piezoelectric power harvesting process anticipated [19].

This paper provides experimental evidences of the piezoelectric power harvesting densities from a prototype apparatus under various heating/cooling temperatures. And, experimental proofs indicating the higher piezoelectric power harvesting density with a denser main operating medium (i.e. water with dissolving a metal-salt) are shown. All the data are of course discussed in details, and future strategies for improving the prototype piezoelectric power harvesting apparatus are declared throughout this paper [20].

\section{Experimental}

\subsection{Experimental Apparatus}

Figure 1 shows a schematic drawing of the experimentally-manufactured piezoelectric power harvesting apparatus for recovering low-temperature-wasteheats less than $373 \mathrm{~K}$. The prototype apparatus was an airtight rectangular paralleled piped liquid bath, where four lateral sides were made of SUS304, possessing a horizontal cross section with $100 \mathrm{~mm}$ on a side and $145 \mathrm{~mm}$ in height. An adiabatic polycarbonate plate, where two cylindrical copper heaters were introduced through, was stuck on the bottom. A SUS304 plate cover with SUS304 bipartite parallel cooling tubes was placed on the top. A discotic piezoelectric 
element having $20 \mathrm{~mm}$ in diameter and $1 \mathrm{~mm}$ in thickness, of which the model number was C- 6 merchandised by Fuji Ceramics Corporation and the resonant frequency was $2 \mathrm{MHz}$, was attached on the lateral side so as to be exposed to an operating medium through an organic thin film.

\subsection{Experimental Procedures}

Firstly, $0.10 \mathrm{dm}^{3}$ of NOVEC and $1.0 \mathrm{dm}^{3}$ of water were poured into the liquid bath. Here, NOVEC manufactured by $3 \mathrm{M}$ Japan Ltd. is quite an unparalleled medium, and its incomparability is pointed out in Table 2 [21] [22].

These distinct properties and characteristics of NOVEC provoke a separated medium macroscopically when it is intermixed with water, coming coincidentally across a biphasic medium of underlying NOVEC and upper-layered water while it stands still [1] [2] [3]. Furthermore, this distinguishing NOVEC allows any constituent materials for appliances since only NOVEC exposes them permanently, resulting that the copper heaters, which is easily decayed in water, can be utilized.

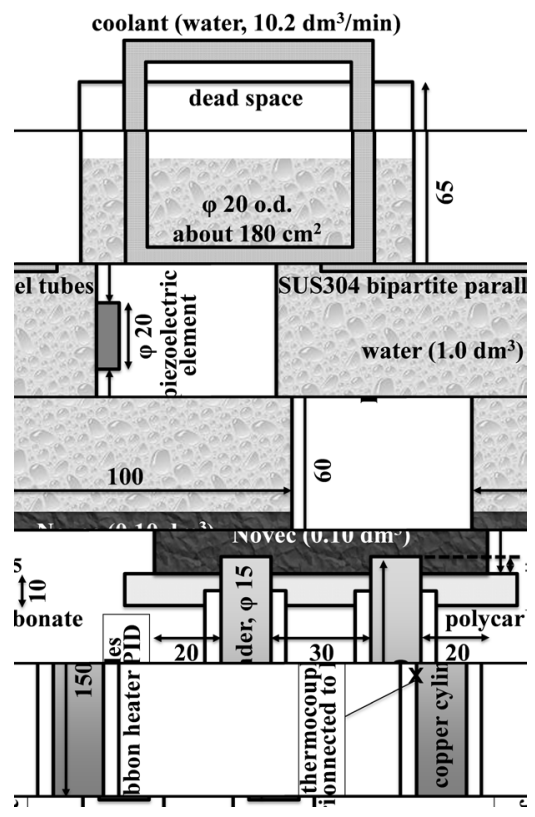

Figure 1. Schematic drawing of piezoelectric power generator for recovering low-temperature-heats.

Table 2. Properties and characteristics of NOVEC.

\begin{tabular}{cccc}
\hline & NOVEC & & Water \\
\hline specific density $[-]$ & 1.41 & $>$ & 1.0 \\
boiling point $[\mathrm{K}]$ & 307 & $<<$ & 373 \\
latent heat of vaporization $\left[\mathrm{kJ} \cdot \mathrm{kg}^{-1}\right]$ & 142 & $<<$ & 2254 \\
specific heat $\left.\left[\mathrm{kJ} \cdot \mathrm{kg}^{-1} \cdot \mathrm{K}^{-1}\right)\right]$ & 1.3 & $<$ & 4.2 \\
extremely low water solubility $(<50 \mathrm{ppm})$ & & \\
extremely low corrosion effect &
\end{tabular}


Secondly, cooling water at less than the boiling-point of NOVEC was circulated at $10.2 \mathrm{dm}^{3} / \mathrm{min}$ through the SUS304 bipartite parallel cooling tubes, where Reynolds number was about 7500 . Thirdly, the cylindrical copper heaters were heated up to a predetermined heating temperature by means of thermocouples attached, ribbon heaters and PID controllers.

Generated voltages from the prototype apparatus approached respective steady values with small fluctuations after individual transition time within 20 min. Consequently, such steady values were logged for more than $60 \mathrm{~min}$ by an oscilloscope (NR-500, KEYENCE Corporation, Japan) with an uptake-rate of 1 MHz. Finally, each mean voltage calculated from the gigantic raw data was converted into the power harvesting density.

\subsection{Expected Power Harvesting Steps}

One of the most indispensable prerequisites for this piezoelectric power harvesting process is a "dead space" at the top part of the liquid bath as shown in Figure 1, otherwise no phase changes arise inside the airtight apparatus. Basically, the dead space enables vaporization and condensation of NOVEC, which make the power harvesting steps denoted in Table 3 expectable [20].

The surfacing vapor bubbles and precipitating droplets of NOVEC definitely accompany the biphasic medium in their wake fields, inducing vigorous and fluctuating medium flows. Naturally, all steps described in Table 3 should be simultaneously enacted. All potential phenomena and their induced events may act synergistically in enlarging the confrontive piezoelectric power harvesting sources of static/kinetic pressure fluctuations and momentum fluxes of water, NOVEC and the NOVEC/water biphasic medium.

\section{Results and Discussion}

\subsection{Visual Observations and Preliminary Demonstrations}

Before going to precise discussions with experimental data under various heating

Table 3. Expected power harvesting steps.

\begin{tabular}{|c|c|c|c|}
\hline Step & Phenomena & Induced events & $\begin{array}{c}\text { Confrontive power } \\
\text { sources }\end{array}$ \\
\hline 1. & $\begin{array}{l}\text { low-temperature-heat transfer } \\
\text { to underlying NOVEC }\end{array}$ & $\begin{array}{l}\text { NOVEC vaporization } \\
\text { (pressurization) }\end{array}$ & $\begin{array}{l}\text { static pressure } \\
\text { fluctuations }\end{array}$ \\
\hline 2. & $\begin{array}{l}\text { surfacing NOVEC vapor bubbles } \\
\text { through underlying NOVEC } \\
\text { and upper-layered water }\end{array}$ & $\begin{array}{l}\text { vigorous/fluctuating flows } \\
\text { of water and NOVEC }\end{array}$ & $\begin{array}{l}\text { momentum flux } \\
\text { kinetic pressure } \\
\text { fluctuations }\end{array}$ \\
\hline 3. & $\begin{array}{c}\text { heat exchange } \\
\text { between NOVEC vapor and water }\end{array}$ & & $\begin{array}{l}\text { static pressure } \\
\text { fluctuations }\end{array}$ \\
\hline 4. & $\begin{array}{c}\text { precipitating NOVEC droplets } \\
\text { through water layer } \\
\text { to underlying NOVEC }\end{array}$ & $\begin{array}{l}\text { NOVEC condensation } \\
\text { (depressurization) }\end{array}$ & $\begin{array}{l}\text { momentum flux } \\
\text { kinetic pressure } \\
\text { fluctuations }\end{array}$ \\
\hline 5. & \multicolumn{2}{|c|}{$\begin{array}{l}\text { entropy discharge outside } \\
\text { exchange between water and coolant }\end{array}$} & \\
\hline
\end{tabular}


and cooling temperatures, it can be clearly declared that all the anticipated phenomena and their induced events described in Table 3 can be confirmed by visual observations with the prototype apparatus excluding the copper cover. Similar appearances inside the prototype apparatus and metallic luster of the copper heaters are preserved for more than $300 \mathrm{~min}$. The piezoelectric power driven by low-temperature-heats can be universally generated from the prototype apparatus in a great reproducible fashion, irrespective of any operable parameters. Hence, all the phenomena and events, which are directly observed without the opaque copper cover, must come off inside the original apparatus with the cover as well. No leakage of the NOVEC/water biphasic medium from the prototype apparatus and no damage of the piezoelectric element are also ascertained over a prolonged period.

\subsection{Effect of Heating Temperature on Power Harvesting Density}

Figure 2 shows power harvesting densities with various heating temperatures less than $373 \mathrm{~K}$ under a constant cooling temperature of $293 \mathrm{~K}$. It is seen that the piezoelectric power can be generated even under a quite low heating temperature of $303 \mathrm{~K}$ (i.e. less than the NOVEC boiling-point of $307 \mathrm{~K}$ ), but that value is negligibly small because of slight convective motions of water and NOVEC. As logical consequences from thermodynamic principles as mentioned predictively in Section 2.3., the higher power harvesting densities come out with the higher heating temperatures above $307 \mathrm{~K}$ of the NOVEC boiling-point. Quantitatively, the piezoelectric power harvesting density of $67.3 \mathrm{pW} / \mathrm{dm}^{2}$ appears with the highest heating temperature of $353 \mathrm{~K}$ in this study.

Needless to state, further elevations of the power harvesting densities can bring to fruition with further increments of the heating temperature. However, exceeding NOVEC vaporizations due to further increasing the heating temperatures might cause exposures of the copper heaters to water as well as extreme pressurization inside the prototype apparatus, yielding some inconveniences such as decay of the heaters, medium breakage and breakage failures of the apparatus. In order to restrain such drawbacks, rise of the NOVEC depth, cooling capacity improvements and structural alterations as switching the apparatus from the current airtight to an open system are considered beneficial.

Here, NOVEC ratio in the biphasic medium can be scarcely raised widely since NOVEC is too expensive about $\$ 100 / \mathrm{kg}$. Ideas to reduce the NOVEC ratio with rising its depth are eclectic such as applying a taper-shape bottom and placing some fillings at the bottom like copper wools [1] [3].

If the open system is adopted, no NOVEC transpirations outside the system must be at least certified for the continual piezoelectric power generation with a great cost performance. Thus, the sufficient cooling capacity must be required for assured condensations of NOVEC vapors inside the system. Then, the effect of cooling temperature on the piezoelectric power harvesting densities is going to be discussed in the next section. 


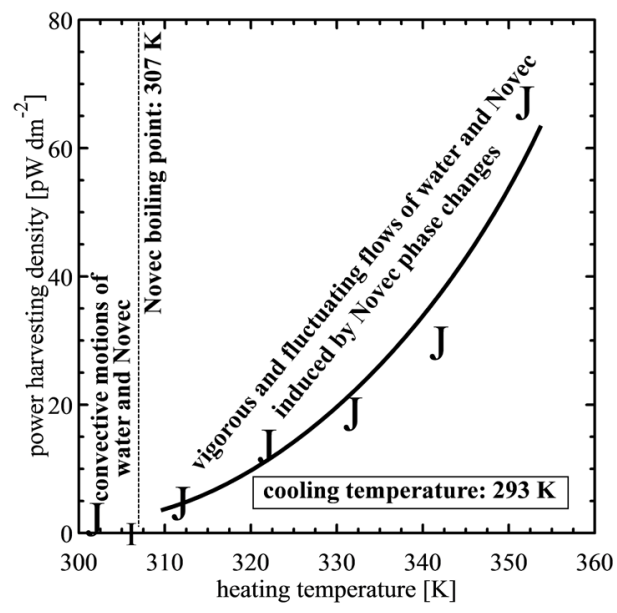

Figure 2. Power harvesting densities with various heating temperatures.

\subsection{Effect of Cooling Temperature on Power Harvesting Density}

Figure 3 shows power harvesting densities with various cooling temperatures under a constant heating temperature of $353 \mathrm{~K}$. Rightfully, the cooling temperature has been adjusted up to the NOVEC boiling-point of $307 \mathrm{~K}$ so as that NOVEC vapor can be condensed inside the prototype apparatus for its long-lasting stable operation.

It can be seen that the piezoelectric power harvesting density is proportionally increased with an increase in the cooling temperature. This is attributed that misspent input heats consumed away as sensible heats of NOVEC up to its boiling-point of $307 \mathrm{~K}$ are inversely proportional to the cooling temperatures. Hence, the optimal cooling temperature is conclusively a little less than the NOVEC boiling-point for the current airtight apparatus.

In order to achieve assured condensations of NOVEC vapors even when the system was open to ambient as stated in the last paragraph of the foregoing section under the higher cooling temperature close to the NOVEC boiling-point, structural alterations and/or supplementary items such as a cooling area enlargement [23], a turbulence eddy accelerator installation [24] and powders entrainment [25] [26] are considered fruitful.

Above-mentioned alterations and/or items in orderly fashions can contribute to improvement of the piezoelectric power harvesting density as well. As be easily conceived from Table 3, a denser operating medium also has so much potential to improve the power harvesting density, then two kinds of biphasic media composed of underlying NOVEC and upper-layered metal-salt aqueous solutions (i.e. denser main medium towards pure water) are tested and discussed in the following two sections.

\subsection{Power Harvesting with NOVEC/Sodium-Chloride-Solution Biphasic Medium}

Figure 4 shows a time trend of power harvesting density with a biphasic me- 
dium of NOVEC and $0.10 \mathrm{~mol} / \mathrm{dm}^{3}-\mathrm{NaCl}$-aqueous-solution under constant heating and cooling temperatures of 353 and $293 \mathrm{~K}$, respectively. The power harvesting density increases monotonically during the early stage on an equality with the NOVEC/water biphasic medium case, whereas it never approaches a constant value, by contrast, shifts to decrease rapidly down to almost nothing. Accurately representing, only about $1.8 \mathrm{pW} / \mathrm{dm}^{2}$, which is tantamount to the case with slight convective motions with the original NOVEC/water biphasic medium under constant heating and cooling temperatures of 303 and $293 \mathrm{~K}$ shown in Figure 2, is generated.

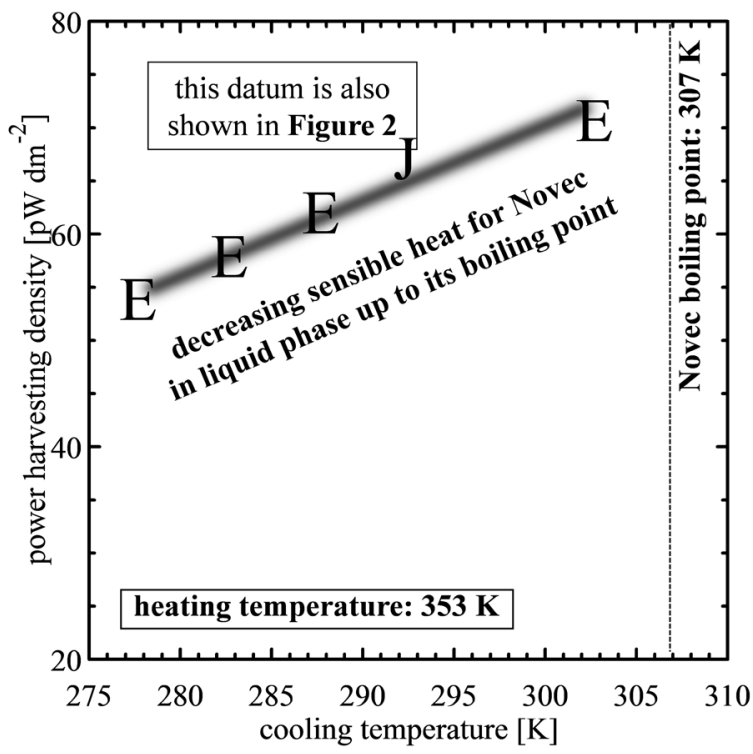

Figure 3. Power harvesting densities with various cooling temperatures.

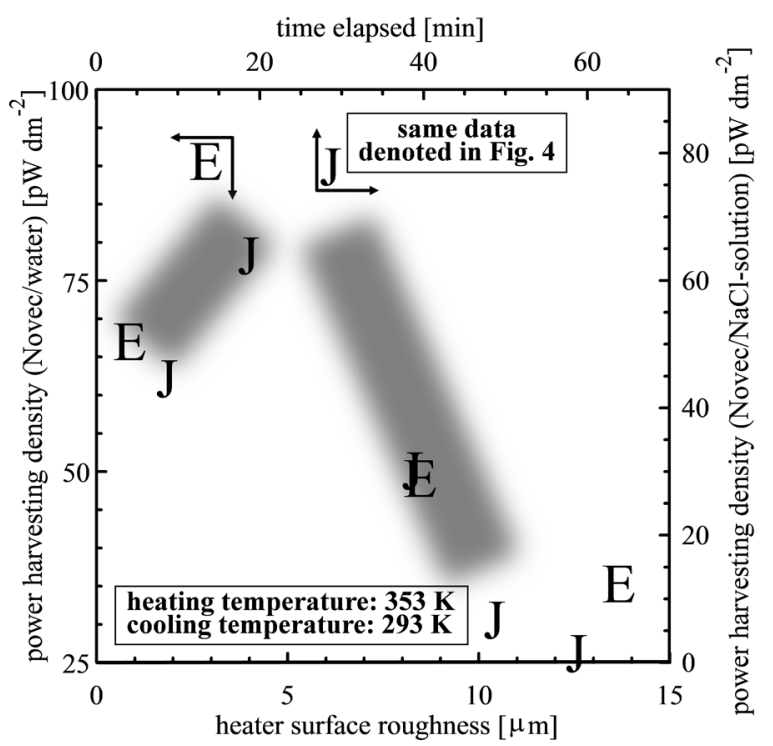

Figure 4. Time trend of pwer harvesting density with NOVEC/NaCl-aquious-solution. 
By means of visual observations before and after the experiment, the initial colorless $\mathrm{NaCl}$-aqueous-solution turns to be tinged with a greenish coloration, denoting that the copper heaters sometimes exposes to the $\mathrm{NaCl}$-aqueous-solution due to lowering the NOVEC depth for its vaporization and concomitant turbulent boundaries between NOVEC and the solution, and then the copper heaters must be dissolved. Therefore, morphological characteristics of micro-cavities on the heater surfaces, which govern nucleate boeing behaviors as well as nucleations of NOVEC vapor bubbles, are considered to suffer lethal influences [27] [28]. So as to certify the correlations between the micro-cavities and power harvesting densities, experiments have been done with the original NOVEC/water biphasic medium under various surface roughnesses of the copper heaters by changing the number of times for scratching them with 60 mesh sandpaper. [1]

Figure 5 shows power harvesting densities with various surface roughnesses of the copper heaters, superimposing all data plotted in Figure 4. Regardless of complete discrepancies in operating parameters, utilized medium, time span and so on, a good analogy can be obtained between solid and hollow circle keys in Figure 5. Accordingly, it is probably guaranteed that chlorine ions in $\mathrm{NaCl}$-aqueous-solution dig the micro-cavities on the copper heater surfaces, providing an inverted $\mathrm{V}$-shaped power harvesting density with time as shown in Figure 4 over Figure 5. Videlicet, Figure 4 and Figure 5 tell a great deal of remaining potentials in further improvement of the power harvesting density by adjusting the micro-cavity characteristics on the copper heater surface such as number density and aperture radii suited for the piezoelectric power generator. The optimal cavities to induce desirable nucleate boiling behaviors must be designed by numerical simulations and referring the literatures [17] [18] [27] [28] [29] [30].

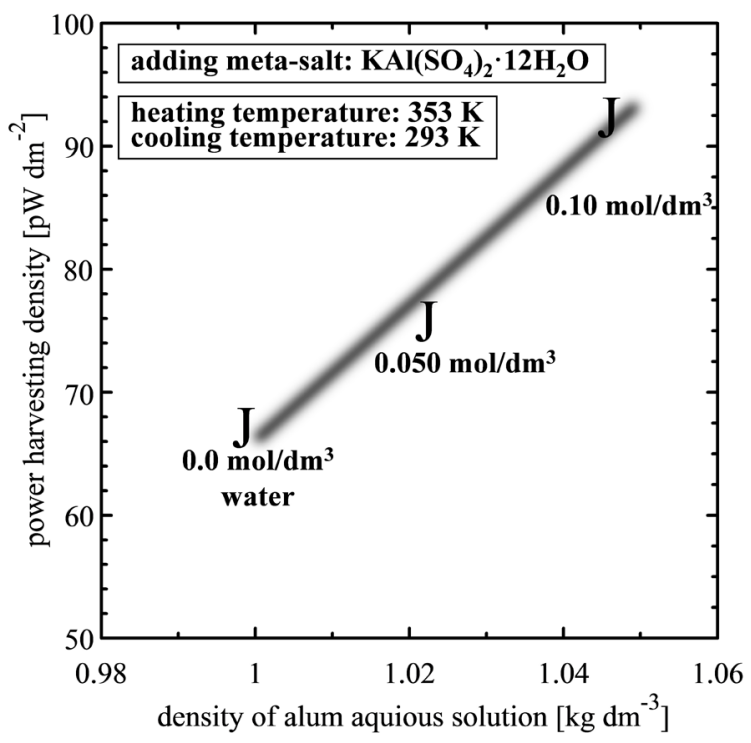

Figure 5. Power harvesting densities with various heater surface roughnesses (data in Figure 4 superimposed). 
In order to prevent such chemical erosions of the copper heaters to disturb power harvesting density, NOVEC increment and silver heaters possessing anti-corrodibility and the champion thermal conductivity as well are promising alterations. Taking cost performance into consideration, the optimal cavities creations on copper heater and other metal-salt dissolved to water can be promising, reaching to alum (aluminum potassium sulfate) solution discussed in the next section.

\subsection{Power Harvesting with NOVEC/Alum-Solution Biphasic Medium}

Figure 6 shows power harvesting densities with a biphasic medium of NOVEC and alum-aqueous-solution having different alum concentrations under constant heating and cooling temperatures of 353 and $293 \mathrm{~K}$, respectively. In the same manner as the NOVEC/water biphasic medium cases, the power harvesting densities with the NOVEC/alum-aqueous-solution approach respective constant values, contrasting to the case with the NOVEC/ $\mathrm{NaCl}$-aqueous-solution shown in Figure 4 over Figure 5.

The increasing piezoelectric power harvesting densities directly proportionate to the alum concentrations emerge. Concretely, the champion power harvesting density of $92.6 \mathrm{pW} / \mathrm{dm}^{2}$, which is about 1.4 times compared to that with the original NOVEC/water biphasic medium, can be procured by using only $5 \%$ denser main operating medium, dissolving alum to water at $0.10 \mathrm{~mol} / \mathrm{dm}^{3}$. This promotion surpasses an anticipated range presumed from the confrontive piezoelectric power harvesting sources of momentum flux and kinetic pressure fluctuations denoted in Table 3. As stated in Chapter 1., approximation of the force impressing frequency to the resonant frequency of the piezoelectric element is favorable for the high performance of the piezoelectric power generation

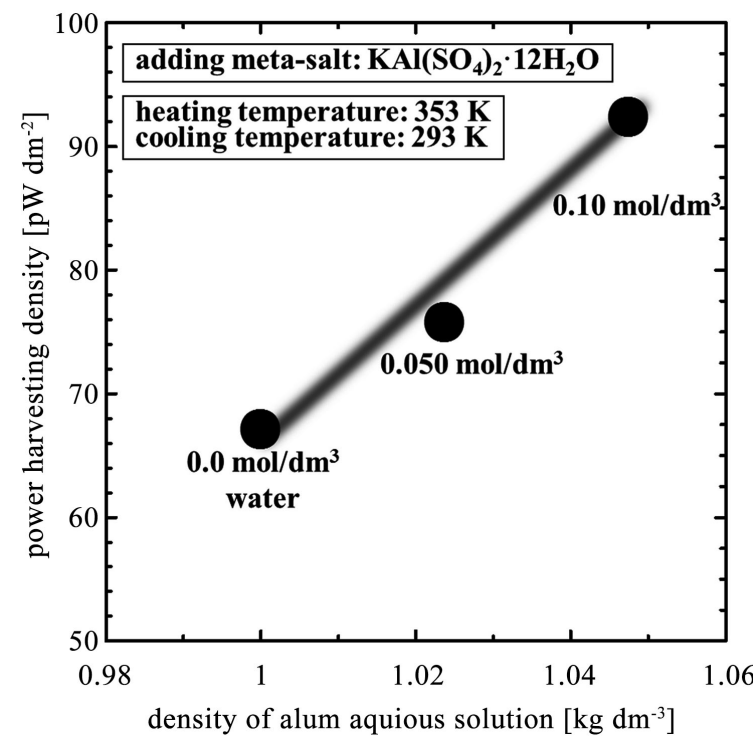

Figure 6. Power harvesting densities with various alum concentrations. 
(i.e. energy harvesting). Accordingly, boiling frequency of NOVEC is considered to increase asymptotically to suit for the prototype piezoelectric power harvesting apparatus owing to chemical and physical properties of the alumaqueous-solution.Thus, enormous fundamental experiments with various metal-salts and its concentrations, statistical approaches and numerical simulations must lead this process to assured practical level [27]-[33].

\section{Conclusions}

In order to reinforce energy recovering technologies from extremely low temperatures less than $373 \mathrm{~K}$, piezoelectric power harvesting process was invented by using unique biphasic operating media of NOVEC/water and/or NOVEC/ alum-aqueous-solution.

The higher power harvesting densities were naturally revealed with increasing heating temperatures. The higher alum concentration in the alum-aqueous-solution was surpassingly helpful for the higher piezoelectric power harvesting density in the case of the NOVEC/alum-aqueous-solution biphasic medium.

Qualitatively, the champion power harvesting density of $92.6 \mathrm{pW} / \mathrm{dm}^{2}$, which was about 1.4 times compared to that obtained with the NOVEC/water biphasic medium, could be obtained by using the NOVEC/alum-aqueous-solution $(0.10$ $\mathrm{mol} / \mathrm{dm}^{3}$ ) biphasic medium, possessing only $5 \%$ denser main operating medium. Further improvements of the piezoelectric power harvesting density could be promising, highlighting their future strategies throughout this paper.

\section{Acknowledgements}

The authors would like to thank 3M Japan Limited for the generous supply of NOVEC. Seiichi Deguchi would like to express deep gratitude to the late Mr. Tatsumi Imura for his kindhearted encouragements and supports.

\section{Conflicts of Interest}

The authors declare no conflicts of interest regarding the publication of this paper.

\section{References}

[1] Deguchi, S., Isu, N., Ichino, Y., Shoichiro, I., Keisuke, S., Ogawa, M., Sakai, K. and Kimoto, K. (2016) Stack-Type Thermoelectric Power Harvesting Module with Flexible Section and Using Phase Changes of Low-Boiling-Point Medium. Energy Conversion and Management, 127, 103-111. https://doi.org/10.1016/j.enconman.2016.08.040

[2] Ogawa, M., Sawada, K., Shimasaki, S., Ito, M., Banno, H., Miwa, S., Kimoto, K., Sakai, K., Deguchi, S. and Isu, N. (2013) Thermoelectric Power Harvesting Device. Japanese Open Patent, No. 2013-157432.

[3] Deguchi, S., Isu, N., Kato, H. and Saeko, M. (2016) Feasibility Demonstrations of Liquid Turbine Power Generator Driven by Low Temperature Heats. Journal of Power and Energy Engineering, Scientific Research, 4, 59-67. https://doi.org/10.4236/jpee.2016.48006 
[4] Shimasaki, S., Banno, H., Ogawa, M., Ito, M., Miwa, S., Sawada, K., Inoue, T., Takagi, K., Deguchi, S., Saito, S., Sano, T., Nozoe, T. and Isu, N. (2013) Piezoelectric Power Harvesting Device. Japanese Open Patent, No. 2013-158138.

[5] Adnan, H. (2011) Energy Harvesting: State-of-the-Art. Renewable Energy, 36, 2641-2654. https://doi.org/10.1016/j.renene.2010.06.014

[6] Henry, A.S., Daniel, J.I. and Gyuhae, P. (2005) Comparison of Piezoelectric Energy Harvesting Devices for Recharging Batteries. Journal of Intelligent Material Systems and Structures, 16, 799-807. https://doi.org/10.1177/1045389X05056681

[7] James, M.G. and Farooq, B. (2008) Comparison of Energy Harvesting Systems for Wireless Sensor Networks. International Journal of Automation and Computing, 5, 334-347. https://doi.org/10.1007/s11633-008-0334-2

[8] Khan, A., Abas, Z., Kim, H.S. and Oh, I.K. (2016) Piezoelectric Thin Films: An Integrated Review of Transducers and Energy Harvesting. Smart Materials and Structures, 25, R1-R16. https://doi.org/10.1088/0964-1726/25/5/053002

[9] Mengying, X., Daniel, Z., Chris, B., Mostafa, A. and Mustafa, A. (2016) Wind-Driven Pyroelectric Energy Harvesting Device. Smart Materials and Structures, 25, R1-R8.

[10] Peigney, M. and Siegert, D. (2013) Piezoelectric Energy Harvesting from Traffic-Induced Bridge Vibrations. Smart Materials and Structures, 22, R1-R11. https://doi.org/10.1088/0964-1726/22/9/095019

[11] Shen, W., Zhu, S. and Zhu, H. (2016) Experimental Study on Using Electromagnetic Devices on Bridge Stay Cables for Simultaneous Energy Harvesting and Vibration Damping. Smart Materials and Structures, 25, R1-R17. https://doi.org/10.1088/0964-1726/25/6/065011

[12] Shu, Y.C. and Lien, I.C. (2006) Analysis of Power Output for Piezoelectric Energy Harvesting Systems. Smart Materials and Structures, 15, 1499-1512. https://doi.org/10.1088/0964-1726/15/6/001

[13] Steven, R.A. and Henry, A.S. (2007) A Review of Power Harvesting Using Piezoelectric Materials (2003-2006). Smart Materials and Structures, 16, R1-R21. https://doi.org/10.1088/0964-1726/16/3/R01

[14] Zhao, J., Ramadass, Y., Lang, J., Ma, J. and Buss, D. (2013) Bias-Flip Technique for Frequency Tuning of Piezoelectric Energy Harvesting Devices. Journal of Low Power Electronics and Applications, 3, 194-214. https://doi.org/10.3390/jlpea3020194

[15] Shimasaki, S., Banno, H., Ogawa, M., Ito, M., Inoue, T., Takagi, K., Nozoe, T., Saito, S., Sano, T., Deguchi, S. and Isu, N. (2013) Proposal and Cold-Model Feasibility Study of New Piezoelectric Power Harvesting Process from Low-Temperature Waste Heats Induced by Vapor Pressure in Airtight Chamber. Proceedings of the International Symposium on EcoTopia Science, Nagoya, 13-15 December 2013, $12-20$.

[16] Imaizumi, S., Banno, H., Kato, H., Miwa, S., Takagi, K., Inoue, T., Nozoe, T., Saito, S., Sano, T., Nakai, Y., Sawada, K., Tsuge, J., Tokutake, K., Isu, N. and Deguchi, S. (2013) Theoretical and Experimental Verifications of Proposed Piezoelectric Power Generator Harvesting Waste Heat. Proceedings of the International Symposium on EcoTopia Science, Nagoya, 13-15 December 2013, 21-28.

[17] Genk, M.S.E. and Parker, J.L. (2008) Nucleate Boiling of FC-72 and HFE-7100 on Porous Graphite at Different Orientations and Liquid Subcooling. Energy Conversion and Management, 49, 733-750. https://doi.org/10.1016/j.enconman.2007.07.028

[18] Yeh, H.C. and Griffth, P. (1965) The Mechanism of Heat Transfer in Nucleate Pool 
Boiling Part I: Bubble Initiation, Growth and Departure. International Journal of Heat and Mass Transfer, 8, 887-904. https://doi.org/10.1016/0017-9310(65)90073-6

[19] Kumagai, S. and Kawasaki, T. (1999) Pressure Fluctuation in Microbubble Emission Boiling. Transactions of the Japan Society of Mechanical Engineers, 65, 1055-1060. https://doi.org/10.1299/kikaib.65.1055

[20] Kato, H., Banno, H., Yamada, A., Imaizumi, S., Miwa, S., Sawada, K., Tsuge, J., Tokutake, K., Takagi, K., Inoue, T., Nozoe, T., Saito, S., Sano, T., Nakai, Y., Isu, N. and Deguchi, S. (2013) Proposal and Experimental Verifications of Piezoelectric Power Generator Due to Pressure Fluctuations of Water Low-Boiling Temperature-Medium. Proceedings of the International Symposium on EcoTopia Science, Nagoya, 13-15 December 2013, 35-42.

[21] http://www.mmm.co.jp/emsd/fluorine/products/fluorinert.html

[22] http://www.mmm.co.jp/emsd/fluorine/products/novec7000.html

[23] Hirota, Y., Sugiyama, Y., Kubota, M., Watanabe, F., Kobayashi, N., Hasatani, M. and Kanamori, M. (2008) Development of a Suction-Pump-Assisted Thermal and Electrical Hybrid Adsorption Heat Pump. Applied Thermal Engineering, 28, 1687-1693. https://doi.org/10.1016/j.applthermaleng.2007.11.012

[24] Bando, Y., Kato, T., Yasuda, K., Sakurai, Y. and Nakamura, M. (1999) Wastewater Treatment by Anaerobic-Aerobic Activated Sludge Method in Bubble Column with Draft Tube. Journal of Chemical Engineering of Japan, 32, 770-775. https://doi.org/10.1252/jcej.32.770

[25] Muroyama, K. and Fan, L.S. (1985) Fundamentals of Gas-Liquid-Solid Fluidization. AIChE Journal, 31, 1-34. https://doi.org/10.1002/aic.690310102

[26] Newson, I.H. (1966) Foam Separation: The Principles Governing Surfactant Transfer in a Continuous Foam Column. Journal of Applied Chemistry, 16, 43-49. https://doi.org/10.1002/jctb.5010160203

[27] Benjamin, R.J. and Balakrishnan, A.R. (1997) Nucleation Site Density in Pool Boiling of Binary Mixtures: Effect of Surface Micro-Roughness and Surface and Liquid Physical Properties. The Canadian Journal of Chemical Engineering, 75, 1080-1089. https://doi.org/10.1002/cjce.5450750611

[28] Hutter, C., Sanna, A., Karayiannis, T.G., Kenning, D.B.R., Nelson, R.A., Sefiane, K. and Walton, A.J. (2013) Vertical Coalescence during Nucleate Boiling from a Single Artificial Cavity. Experimental Thermal and Fluid Science, 51, 94-102. https://doi.org/10.1016/j.expthermflusci.2013.07.005

[29] Gils, R.W., Damilov, D., Notten, P.H., Speetjens, M.F. and Nijmeijer, H. (2014) Battery Thermal Management by Boiling Heat-Transfer. Energy Conversion and Management, 79, 9-17. https://doi.org/10.1016/j.enconman.2013.12.006

[30] Fujisawa, M. and Miura, K. (2009) Volume Preserving Nucleate Boiling Simulation. Visual Computing, 38, 441-448.

[31] Deguchi, S., Deguchi, M. and Nishimura, A. (2003) Development of an Airtight Oscillating Fluidized Bed. Kagaku Kogaku Ronbunshu, 29, 493-498. https://doi.org/10.1252/kakoronbunshu.29.493

[32] Deguchi, S., Mizuno, T., Matsuoka, K., Nishimura, A. and Nasu, H. (2003) Algebraic Expression of the Minimum Gas Velocity Restraining Downward-Flowing Particles through the Contraction Midway of a Circulating Fluidized Bed Riser. Kagaku Kogaku Ronbunshu, 29, 660-666. https://doi.org/10.1252/kakoronbunshu.29.660

[33] Deguchi, S. (1999) Simulation for Solid Concentration Profile in CFB with Different Fluid/Solid Density Ratios. Chemical Engineering Science, 54, 5507-5513. 